\title{
Martín-Baró como Inspiração Ética para a Construção de uma Perspectiva
}

\section{Comunitária e Popular em Psicologia}

\author{
Mariana Alves Gonçalves* \\ Centro Universitário Celso Lisboa, Rio de Janeiro, RJ, Brasil \\ ORCID: https://orcid.org/0000-0002-9040-6009
}

\begin{abstract}
RESUMO
A partir de estudos históricos sobre a trajetória da Psicologia social comunitária no Brasil, pretendemos neste artigo explorar as contribuições de um dos maiores autores da psicologia latino-americana, Ignacio Martín-Baró para a construção de uma perspectiva popular em psicologia. Percorrendo a publicação da tradução de seus textos no Brasil, que acontece de forma expressiva muito recentemente, sistematizamos os principais pontos de seus escritos que nos servem como inspiração ética e política para pensarmos a construção de uma perspectiva comunitária e popular em psicologia. Sua contribuição se coloca como caminho para a construção de horizontes de práticas genuinamente comprometidas com as pautas e questões populares, já que sempre preconizou a produção de uma psicologia a partir do povo e sua realidade.
\end{abstract}

Palavras-chave: história da psicologia, psicologia popular, Martín-Baró.

\section{Martín-Baró as an Ethical Inspiration for Building a Community and}

\section{Popular Perspective on Psychology}

\begin{abstract}
From historical studies on the trajectory of community social psychology in Brazil, we intend in this article to explore the contributions of one of the greatest authors of Latin American psychology, Ignacio Martín-Baró to the construction of a popular perspective in psychology. Going through the publication of the translation of his texts in Brazil, which happens very recently, we systematize the main points of his writings that serve as an ethical and political inspiration for us to build a community and popular perspective in psychology. His contribution stands as a way to build horizons of practices genuinely committed to the popular issues, since he always advocated the production of a psychology from the people and their reality.
\end{abstract}

Keywords: history of psychology, popular psychology, Martin-Baró.

ISSN 1808-4281 


\section{Martín-Baró como una Inspiración Ética para la Construcción de una}

\section{Perspectiva Comunitaria y Popular en Psicología}

\section{RESUMEN}

A partir de estudios históricos sobre la trayectoria de la Psicología social comunitaria en Brasil, pretendemos en este artículo explorar las contribuciones de uno de los más grandes autores de la psicología latinoamericana, Ignacio Martín-Baró, a la construcción de una perspectiva popular en psicología. Al pasar por la publicación de la traducción de sus textos en Brasil, que ocurre expresivamente muy recientemente, sistematizamos los puntos principales de sus escritos que sirven de inspiración ética y política para que construyamos una perspectiva comunitaria y popular en psicología. Su contribución se erige como una forma de construir horizontes de prácticas genuinamente comprometidas con la agenda y los temas populares, ya que siempre abogó por la producción de una psicología de las personas y su realidad.

Palabras clave: historia de la psicología, psicología popular, Martin-Baró.

Aos psicólogos latino-americanos nos faz falta um bom banho de realidade, especialmente dessa realidade que oprime e angustia as maiorias populares. (MartínBaró, 1987/2017, p. 78).

A partir de estudos históricos sobre a trajetória da Psicologia social comunitária no Brasil (Gonçalves, 2013, 2019; Gonçalves \& Portugal, 2016) e também de algumas intervenções sociais da psicologia (Gonçalves, 2013, 2019), pretendemos neste artigo explorar as contribuições de um dos maiores autores da psicologia latino-americana, Ignacio Martín-Baró para a construção de uma perspectiva popular em psicologia. Partimos de Martín-Baró como inspiração ética e política, pois não entendemos que seu legado prático e teórico como militante e psicólogo el salvadorenho possa ser usado somente como instrumental analítico para historiar as intervenções sociais brasileiras. Sua contribuição se coloca como caminho para a construção de horizontes de práticas genuinamente comprometidas com as pautas e questões populares, já que sempre preconizou a produção de uma psicologia a partir do povo e sua realidade. Ou seja, que possamos produzir práticas e pesquisas a partir do que Martín-Baró o fez e não somente utilizar seus textos como ferramentas de análise e estudos bibliográficos.

A partir de nossos estudos e partindo da análise das práticas comunitárias no Brasil (Gonçalves, 2019), entendemos que a nós psicólogos, falta um banho de favela. Por isso, 
primeiro fazemos uma convocação aos leitores deste artigo: que nos deixemos angustiar e impactar pela realidade em que vivem as maiorias populares, em nosso caso, os favelados. Partindo desta convicção, reafirmando os pressupostos no qual nos inserimos: a defesa e a busca de uma perspectiva popular para as intervenções sociais e comunitárias da psicologia. Recorremos a Martín-Baró também para afirmar que nosso campo de disputa é a psicologia, como foi o dele. Não se trata de dizer que, a despeito de reconhecermos a importância de processos emancipatórios, isto não será feito pela psicologia em seu cotidiano de trabalho. A proposta de uma psicologia popular e a lucidez dos escritos de Martín-Baró inspiram os escritos deste trabalho. Esta inspiração teórica e ético-política se configura pela proposta enfática de Martín-Baró na contribuição da psicologia nos processos de transformação social.

Como construir um projeto de base popular na psicologia? Este projeto já existe? A PSC representou este projeto? O que define o povo, e, portanto, esta perspectiva popular? As condições de opressão em que vivem as pessoas em favelas pode ser traduzida pela condição de opressão dos trabalhadores? Ou seja, a luta dos favelados é a luta dos trabalhadores?

Foi a partir de uma pesquisa de doutorado que tinha como objetivo mapear os encontros entre psicologia e favela na cidade do Rio de Janeiro, com a perspectiva de analisar a presença de uma perspectiva popular nos projetos comunitários psi e delirar a construção de um horizonte de transformação na psicologia que denominamos psicologia favelada, que construo o texto aqui apresentado. A partir de problematizações realizadas no campo da Psicologia Social Comunitária, realizamos alguns deslocamentos para pesquisar o trabalho comunitário do psicólogo no contexto carioca. Tendo como horizonte a possibilidade de construção de uma perspectiva popular em psicologia, como demonstrado no trabalho de Ignacio Martín-Baró, mapeamos o trabalho de psicólogos e destacamos as lutas populares da favela como fontes de inspiração para a invenção de novas práticas e um novo horizonte para a psicologia a partir de sua favelização.

\section{As Pistas de Martín-Baró para a Construção de uma Perspectiva Popular}

Martín-Baró, como um representante do esforço de colocar a psicologia contra a ordem (Lacerda Jr., 2017), é uma inspiração fundamental para esta proposta. Uma referência para pensar uma psicologia organicamente vinculada às questões populares. A atualidade da obra de Martín-Baró representa, segundo Lacerda Jr e Guzzo (2009), a construção de uma perspectiva crítica em psicologia baseada no "resgate da crítica marxista; no resgate da 
realidade, como ponto de partida e de chegada; e a libertação, como fim e projeto históricos de massas" (p. 19).

É importante destacar a que nos serve a inspiração em Martín-Baró neste texto. Para nós, o que se destaca em sua obra é a crítica contundente que dirige à psicologia e algumas pistas sobre a sua reconstrução teórica e epistemológica a partir do povo. Em resumo, o que é a psicologia favelada se não uma reivindicação para a atualização radical de uma crítica à psicologia? E também de uma reivindicação à reflexão sobre seu distanciamento das lutas e movimentos populares? A psicologia favelada atualiza, portanto, dentro do contexto brasileiro e carioca, os problemas colocados à psicologia no contexto el salvadorenho.

Martín-Baró escreveu sobre diferentes temas vinculados à sua realidade el salvadorenha, como questões relativas ao machismo e à violência. No entanto, cabe destacar que a conexão de sua obra com este texto se faz a partir de sua crítica à psicologia e às propostas lúcidas e claras sobre como construir novos caminhos conceituais e práticos para o campo. Apesar destes tópicos atravessarem toda a sua obra, alguns trabalhos tratam este problema de forma mais expressiva. São estes que trazemos aqui a fim de alimentar as reflexões sobre os encontros entre psicologia e favela.

Quando inicia um de seus textos de maior circulação no Brasil - O papel do psicólogo -, Martín-Baró (1985/1996, p. 7) afirma: “o trabalho profissional do psicólogo deve ser definido em função das circunstâncias concretas da população a que deve atender". Essa simples e categórica afirmação é seguida por uma análise de conjuntura da situação de opressão da população el salvadorenha. A proposta do autor é, portanto, que cada psicólogo, em seu contexto, faça a análise da situação de seus povos. Entendendo que o que define o povo são as suas condições de opressão, na cidade do Rio de Janeiro, a favela é o espaço onde essas condições são mais radicalmente identificadas. O racismo, a exploração e o machismo são algumas das situações de opressão denunciadas pelas favelas. Entendemos o povo como um grupo populacional que sofre múltiplas formas de opressão e nenhuma delas nos parece ser anterior ou superior à outra. Ribeiro (2016, p. 12), ao prefaciar o livro de Angela Davis Mulheres, raça e classe - destaca que "a autora mostra a necessidade de não hierarquização das opressões, ou seja, o quanto é preciso considerar a intersecção de raça, classe e gênero para possibilitar um novo modelo de sociedade". Como o genocídio produzido pelo Estado nestes espaços é o maior motivo de suas bandeiras de luta, o racismo costuma ser destacado pelos movimentos como uma das mais cruéis formas de opressão.

No entanto, é importante dizer que nossa leitura sobre as relações de poder e os processos de opressão não são dicotomizadas, totalizantes e unitárias. Ou seja, entendemos 
que as dominações são produzidas em níveis relacionais, simbólicos, e se reproduzem também dentro desta categoria "povo" que invocamos para pensar outras formas de produzir psicologia. No entanto, cientes disso, entendemos que evocá-la diz respeito também a pensar os diferentes formatos que as estratégias de dominação e opressão podem tomar nestes contextos. Não tomamos o povo como uma categoria que esteja imaculada e asséptica das relações de dominação. Mas, ainda assim, acreditamos que o encontro com a atualização desta categoria nas favelas pode nos inspirar na construção de um novo quehacer psicológico.

Qual é o sentido de um projeto de base popular para a psicologia? Em que direção ele deve caminhar? É a partir desta perspectiva que podemos vislumbrar a reconstrução teórica da psicologia? Ou seja, ao se deixar contaminar pelas questões populares presentes na favela, a psicologia terá a chance de se reconstruir enquanto ciência e profissão? Trata-se de uma reconstrução teórico-epistemológica e metodológica e um novo projeto ético-político para a profissão, a fim de que a psicologia possa se aliar concretamente às lutas por transformação social. Neste sentido, Lacerda Jr (2017) distingue as propostas de Martín-Baró para a Psicologia Social:

não deixar a ciência psicológica alheia às lutas sociais; rejeitar os conceitos que são instrumentais para a reprodução do status quo; e construir uma nova Psicologia, adequada à luta histórica pela edificação de um mundo novo. (Lacerda Jr., 2017, p. 11, grifos do autor).

No texto “O psicólogo no processo revolucionário”, Martín-Baró (1980/2017), ao definir a revolução como uma mudança radical na ordem social, propõe uma perspectiva para o trabalho do psicólogo neste processo: ser um bom psicólogo e ser um psicólogo do povo. Qual é o sentido desta proposta? Ser um bom psicólogo é desvincular sua atuação profissional das estruturas de poder e prever, não no laboratório, mas na realidade, os acontecimentos e os problemas emergentes na construção de uma nova sociedade (Martín-Baró, 1980/2017, p. 28). Sua tarefa é "facilitar e humanizar a passagem à nova sociedade". Mas há também um trabalho imediato: "atender a angústia, o pânico, o stress coletivo que pendem sobre o povo el salvadorenho" (Martín-Baró 1980/2017, p. 28), resultantes do processo de repressão e desumanização social. Ser um psicólogo do povo, diz Martín-Baró,

não é uma questão de intencionalidade: colocar uma ciência fundamentada em termos individualistas e viciados a serviço da comunidade, só resultaria na reintrodução ou 
manutenção das necessidades e vivências do homem "capitalista". A questão é transformar os próprios esquemas de compreensão e de trabalho a partir da perspectiva do povo salvadorenho. Dito de outra maneira, devemos redefinir os próprios fundamentos da ciência psicológica. (Martín-Baró 1980/2017, p. 28-29).

Com a esperança de construção de uma nova sociedade em EL Salvador, Martín-Baró descreve as tarefas fundamentais deste psicólogo em uma nova sociedade. Entre estas funções, entende que o psicólogo deve contribuir para novas formas de convivência social advindas de novas formas de organização do trabalho. Além disso, seria também tarefa de um psicólogo do povo e revolucionário acompanhar o processo de transformação da sociedade a partir das mudanças nas pessoas. As novas bases desta sociedade exigem o desenvolvimento de novos valores e de novas sentidos para as relações sociais. E é esta a tarefa do psicólogo como interventor da dimensão subjetiva e relacional. Seria ele o responsável por ajudar a construir uma sociedade que tem como base os valores do companheirismo, solidariedade e comunidade.

As propostas colocadas por Martín-Baró devem ser contextualizadas e é a esta tarefa que ele nos convoca. O que seria "ser um psicólogo do povo" no contexto brasileiro, no contexto favelado? Portanto, devemos destacar as críticas que Martín-Baró faz à psicologia e tomar como nosso trabalho a necessidade de pensar as bases de construção de uma nova perspectiva.

A distância das questões da maioria da população latino-americana nos faz pensar em uma reestruturação da psicologia em relação à sua concepção de mundo e categorias de análise. Uma psicologia da libertação só se faz libertando-se das teorias e epistemologias que a distanciam das urgências populares. Entender uma psicologia ancorada nas lutas e organizações populares, que critique à psicologia hegemônica e pensar em novas bases que sustentam uma nova psicologia parece resumir os pressupostos da construção de uma perspectiva popular em psicologia.

\section{Um Psicólogo do Povo?}

Diante disso, a perspectiva popular proposta por Martín-Baró para a Psicologia significa necessariamente uma revisão dos seus fundamentos teóricos a partir do ponto de vista do povo, ou seja, das maiorias oprimidas. Além de redefinir concretamente as questões, o cientista não pode enclausurar-se na neutralidade de suas pesquisas. Quando reflete sobre a 
construção de uma nova epistemologia para a Psicologia, Martín-Baró (1986/2009) propõe que devemos redefinir os próprios fundamentos da ciência psicológica. Esta nova perspectiva deve ser orientada a partir das maiorias populares, com uma relativização e revisão crítica realizada a partir destas maiorias (Martín-Baró, 1986/2009, p. 192-193).

Martín-Baró (1986/2009), ao pensar sobre as razões da miséria histórica da psicologia latino-americana, indica alguns fatores que explicam esta condição: o colonialismo, o mimetismo cientificista, a ausência de uma epistemologia adequada e os seus falsos dilemas. É interessante destacar a reflexão sobre os falsos dilemas que assolam a Psicologia, pois assim, Martín-Baró (1986/2009) torna explícito o distanciamento de sua postura em relação a leituras essencializantes e totalitárias. Mesmo tecendo críticas à Psicologia Social norteamericana, ao diferenciar uma psicologia reacionária e uma psicologia progressista, ele diz que o que define estas posições não são os lugares de origem destas psicologias, mas sim a "capacidade para explicitar ou ocultar a realidade e, sobretudo, para reforçar ou transformar a ordem social" (Martín-Baró, 1986/2009, p. 189). O que define o progressismo de uma psicologia é, portanto, sua capacidade e compromisso em ajudar os povos a encontrar o caminho de libertação.

Aqui, destacamos o debate sobre a ausência de uma epistemologia adequada ao evidenciar que os modelos dominantes na psicologia se fundamentam em pressupostos pouco discutidos: positivismo, individualismo, hedonismo, a visão homeostática e o a-historicismo. Sobre o hedonismo, nos parece interessante apresentar sua fala sobre a leitura universal do funcionamento por busca de prazer e satisfação de toda atividade humana. Pergunta-nos Martín-Baró (1986/2009): não seria esta forma de entender o comportamento humano como uma estratégia de naturalizar o dispositivo do lucro, este por sua vez produto do sistema capitalista? Como reconhecer práticas de solidariedade e outras atividades que desviem disto que está sobrecodificado em leituras universais e naturais do ser e estar no mundo, em geral apresentadas pelas teorias hegemônicas em psicologia? Martín-Baró (1986/2009) questiona, por exemplo, o princípio hedonista para compreender de forma universal e natural os comportamentos humanos. Como o princípio hedonista explica a solidariedade identificada por ele em grupos de refugiados em El Salvador? Denuncia, portanto, que estas características supostamente universais e naturais do indivíduo psicológico são produzidas e correspondentes a um determinado modelo de produção econômica. A "natureza" dos comportamentos explicitadas pela psicologia hegemônica mascaram sua produção e expressão de um determinado modelo socioeconômico, o modelo de produção capitalista. Além disso, destaca que a visão homeostática, neste mesmo sentido, tende a capturar sob os signos de 
patologização os conflitos e lutas sociais. Visto como um pressuposto da psicologia hegemônica, Martín-Baró diz que essa visão nos leva a suspeitar de tudo que representa mudança e desequilíbrio.

Deslocando-se desta captura que patologiza as lutas populares, como pensar diante dos conflitos e da gravidade das situações que assolam as maiorias populares? A partir de onde definimos o que é socialmente desejável? Assumindo a perspectiva do povo. Mesmo assumindo que há um processo de alienação fruto de uma consciência, que, por vezes, deseja o que mantém a condição de opressão, Martín-Baró (1985/2017) alerta para as posturas catequizadoras que podemos assumir na tarefa de conscientização. Como se conectar com as necessidades populares sem os retirar do protagonismo de suas reivindicações?

Quem deve, então, determinar as necessidades "verdadeiras" e "falsas"? A quem cabe diferenciar o que há de autêntico e o que há de alienante no interior da consciência popular? Por acaso, deverá o psicólogo social se converter em "intérprete" das necessidades populares? Problema que não é de fácil solução, nem mesmo para aqueles que, surgidos do próprio povo, se convertem em sua vanguarda política, mas que, ao chegarem nesse lugar, frequentemente, perdem o contato existencial com suas bases e tendem a assumir como voz do povo o que não é mais do que a sua própria voz. (Martín-Baró, 1985/2017, p. 81).

Ao assumirmos a necessária tarefa de libertação, os objetivos da psicologia social devem ser: redefinir as suas bases teóricas e fortalecer opções populares. A fim de operacionalizar estes objetivos, a psicologia social deve realizar "o estudo sistemático das formas de consciência popular", "o resgate e a potencialização das virtudes populares" e a “análise das organizações populares como instrumento de libertação histórica”. De nada adianta o processo de conscientização, se dele não resultam "formas organizativas que conduzam os interesses das maiorias populares para o confronto social" (Martín-Baró, 1985/2017, p. 84).

Sobre os desafios colocados à psicologia latino-americana, Martín-Baró (1986/2009, p. 202) define que a psicologia deve redefinir seu papel a partir de três perguntas: uma pergunta epistemológica, uma conceitual e outra prática. A pergunta epistemológica "questiona os critérios de verdade normalmente utilizados para legitimar nosso conhecimento", entendendo que as verdades produzidas nas teorias psicológicas hegemônicas são verdades situadas e não universais. Desta forma, entendendo a constituição histórica dos 
seres humanos, Martín-Baró (1986/2009) nos pergunta como definir critérios de verdade situados a partir da realidade dos nossos povos. Esta seria a pergunta epistemológica que a psicologia latino-americana deve se fazer. Neste mesmo sentido, a questão conceitual diz respeito a avaliar "os problemas específicos dos nossos povos sem as proteções dos marcos teóricos apriorísticos, que filtram, de forma enviesada, a realidade e limitam, não isentos de interesses, nossa capacidade de compreensão" (Martín-Baró, 1986/2009, p. 203). Conectado ao princípio que a realidade é a dimensão de onde se parte e aonde se chega, é ela quem deve balizar a construção de uma nova perspectiva teórica e não o contrário. E a pergunta práxica nos leva a pensar sobre as contribuições concretas que os fazeres científicos e profissionais da psicologia apresentaram historicamente aos povos latino-americanos. Entende que há uma limitação inerente ao quehacer psicológico e que nossa marginalidade aos anseios dos povos não diz respeito a uma falta de disposição ou a um conformismo. É a partir disso que afirma que "a marginalidade da práxis não pode ser atribuída a um conformismo germinal dos psicólogos ou a uma insensibilidade ante os sofrimentos das maiorias, mas, mais provavelmente, a uma impotência intrínseca ao próprio fazer psicológico" (Martín-Baró, 1986/2009, p. 203).

Ainda sobre os desafios colocados à psicologia latino-americana, problematiza sobre o debate em torno da falta de relevância social. Tópico extensamente reivindicado por aqueles que dirigiram críticas à Psicologia Social Cognitiva na chamada "crise" da Psicologia Social, a falta de relevância social era um argumento a justificar o distanciamento das teorias em Psicologia Social da realidade social. Mas Martín-Baró (2009, p. 205) nos pergunta: “onde está a pretensa falta de relevância social?”. A psicologia influencia expressivamente nossa sociedade, mas o fez em relação aos grupos dominantes.

Qual é a perspectiva que Martín-Baró propõe para uma popularização da psicologia? Ao pensar sobre a construção de uma psicologia a partir da favela, o que deve ser tomada como um horizonte para a construção de uma perspectiva popular em psicologia? Qual é a realidade do povo favelado? Como a psicologia pode concretamente construir suas teorias e intervenções a partir dela?

Ainda no texto “O psicólogo no processo revolucionário”, Martín-Baró (1980/2017) indica sua preocupação com o horizonte que devemos ter para contribuir no processo revolucionário. Ele diz a nova sociedade de El Salvador “(a) a prioritária e crescente satisfação das necessidades básicas do povo; (b) a formação de uma nova mentalidade, solidária e comunitária; (c) a busca por uma personalidade social autenticamente nacional e popular" (p. 26). Nós já perguntamos qual é a sociedade almejada pelo nosso povo? A 
psicologia se agencia a esta tarefa ético-política em seu cotidiano, reconhecendo os protagonistas deste processo?

Ao definir as prioridades da construção de uma psicologia popular, Martín-Baró (1989/2009) elenca três tarefas urgentes. A recuperação da memória histórica dos povos precisa resgatar o orgulho de pertencimento dos povos em relação a sua cultura, tradição, valores, onde a necessária "reconstrução de certos modelos de identificação" (p. 216) tem como horizonte a libertação coletiva. Em relação à potencialização de suas virtudes como uma tarefa de construção de uma psicologia popular, Martín-Baró (1989/2009) entende que precisamos "reconhecer e potencializar todas aquelas virtudes próprias de nossos povos que lhes permitiram confrontar, em circunstâncias quase infra-humanas, a difícil tarefa de sobrevivência histórica" (p. 216). Ou seja, o autor chama a atenção para as estratégias de resistência historicamente já utilizadas pelos povos em sua história. Cita, por exemplo, a inteligência prática de crianças marginalizadas ou a solidariedade do camponês el salvadorenho, evidenciando os modos de funcionamento presentes no cotidiano dos povos que expressam suas formas de resistência que escapam às formulações teóricas revolucionárias. Os povos resistem, precisam resistir ao nível da sua sobrevivência. Neste sentido, vemos uma estreita conexão com a proposta de uma perspectiva popular em psicologia. Por fim, defende que uma psicologia popular precisa de um trabalho conscientizador. Tese já explorada no texto $O$ papel do psicólogo, a conscientização requer uma práxis transformadora das dimensões sociais e materiais que esteja atenta aos "interesses mais autênticos das próprias classes populares" (Martín-Baró, 1989/2009, p. 217). Ao afirmar que a psicologia popular precisa ser uma psicologia política, diz que precisamos levar em conta “o poder social na configuração do psiquismo humano" (Martín-Baró, 1989/2009, p. 217). No entanto, Martín-Baró (1989/2009) alerta para os perigos da mitificação dos povos e da psicologia popular. No entanto, é preciso resgatar os processos de pensamento e atuação dos povos, que os fizeram resistir a história de dominação e imperialismo.

Assim como Martín-Baró, nos inspiramos em Paulo Freire para refletir sobre esta categoria popular e seus processos de libertação. No livro Pedagogia do oprimido, o autor apresenta a relação dinâmica entre oprimidos e opressores e entende que o horizonte de libertação é a superação desta contradição e destas relações. O destaque é para a necessária reflexão sobre como os oprimidos, as maiorias populares, o povo, são permeados pelas formas de dominação do opressor. Como construir o protagonismo de suas lutas entendendo que neles habitam também o modo de funcionamento opressor? 
A categoria popular precisa ser pensada de forma processual e múltipla, sem deixar de considerar a dimensão estrutural das dominações sociais, econômicas e políticas. Não há como entender o povo como unidade livre da reprodução das dominações produzidas socialmente. Os oprimidos hospedam em si a sombra dos opressores, diz Freire (1967/2011). Entendemos que o horizonte das lutas populares é que não tenhamos oprimidos que desejam se tornar opressores. O horizonte deve estar na superação da contradição. Como diz Freire (1967/2011, p. 60): “os oprimidos de ontem, que detém os antigos opressores em sua ânsia de oprimir, estão gerando, com seu ato, liberdade, na medida em que com ele, evitam a volta do regime opressor”. A necessária superação deste nível de dominação simbólica para a transformação social parece ser um importante horizonte revolucionário. A tarefa constante de não reproduzir relações de dominação ao construir resistências baseadas em relações dialógicas, que não estejam agenciadas com a violência, os silenciamentos, o autoritarismo e a desumanização, nos parece fundamental. Só há superação da opressão se a contradição da relação for superada e não se instauramos novos polos opressores versus oprimidos.

\section{Considerações Finais}

Ao entendermos que a construção de uma perspectiva popular em psicologia está ancorada em uma aproximação das questões que afligem o povo e sua realidade, nos cabe também discutir de que realidade se trata. Apesar de tomarmos a realidade como evidência, como aquilo que se apresenta como a urgência e a materialidade cotidiana dos povos, que está sempre deixada do lado de fora dos consultórios e das análises psicológicas, Freire (1967/2011) nos convoca a pensá-la em articulação com os processos de transformação.

A realidade social, objetiva, que não existe por acaso, mas como produto da ação dos homens, também não se transforma por acaso. Se os homens são produto desta realidade e se esta, na "inversão da práxis", se volta sobre eles e os condiciona, transformar a realidade opressora é tarefa histórica, é tarefa dos homens. (Freire, 1967/2011, p. 51)

Portanto, a perspectiva popular proposta por Martín-Baró é uma inspiração à psicologia favelada e também a psicologia social e comunitária. Mas destacamos que a análise das situações de opressões reais e concretas oferecem singularidade aos processos identificados nas favelas em relação, por exemplo, ao povo el salvadorenho. Esta utópica 
psicologia favelada deve caminhar em um horizonte popular, mas nem toda psicologia popular pode ser resumida a psicologia favelada. A favela é um dos lugares de circulação do povo e sua experiência de vida neste espaço da cidade singulariza sua condição de opressão. Existir como povo na favela significa estar exposto, por exemplo, a uma violência do Estado e à condição de exceção quando abordamos a garantia de direitos. Ao entender como povo o conjunto de pessoas que sofre algum tipo de opressão, é preciso dizer que há uma complexa variedade de opressões sofridas mais radicalmente pelo povo da favela. Elas se pulverizam entre as questões econômicas, políticas, de raça e gênero. Mas o que se destaca quando precisamos qualificar o sofrimento entre que os moram em favelas, é preciso destacar o genocídio produzido pelo Estado e sua violência cotidiana. Sua luta, portanto, se resume, muitas vezes, em uma legítima e aguerrida luta pela vida.

Quem vai nos ensinar a construir uma perspectiva popular? O povo. Dizer isso é destruir lugares de saber, especialismos, academicismos. A Psicologia Favelada reivindica uma perspectiva popular à Psicologia. Ela poderia ser chamada de Psicologia popular, porque está no conjunto de sua proposta: a libertação da Psicologia e sua refundação em bases teóricas e epistemológicas construídas a partir do povo. Martín-Baró é uma inspiração para a construção desta perspectiva, mas é sempre necessário fazer as devidas contextualizações. Além de suas ideias serem desenvolvidas em um cenário específico de El Salvador, seu convite aos psicólogos latino-americanos era justamente que nós construíssemos um horizonte popular para a Psicologia a partir das características de nosso povo. A psicologia popular, portanto, no cenário do Rio de Janeiro, se atualiza nas favelas e pode ser pensada a partir deste espaço da cidade. Esta é a radicalidade na escolha da realidade como ponto de partida, que caracteriza a proposta do realismo crítico. Esta orientação se aproxima da ideia de que devemos analisar concretamente as condições de vida na favela para pensar as contribuições teóricas e intervenções. Parte-se da favela para a favela. Somente uma aposta na realidade pode produzir uma intervenção emancipatória, com o horizonte de libertação (Lacerda Jr. \& Guzzo, 2009). Colocamos aqui ainda a necessidade de Martín-Baró ser tomado como inspiração ética, como orientação para ações inspiradas a partir de sua perspectiva. E não tomá-lo como referencial explicativo e interpretativo das realidades dos povos em qualquer contexto. Reconhecer que sua obra não possui uma homogeneidade teórica e que algumas de suas propostas são circunscritas ao contexto elsalvadorenho, não nos impede de tomar MartínBaró como referência para a afirmação e reivindicação de uma psicologia pautada e orientada para a realidade. 


\section{Referências}

Freire, P. (2011). Pedagogia do oprimido (50a ed.) Rio de Janeiro: Paz e Terra. (Obra original publicada em 1967)

Gonçalves, M. A. (2013). Uma análise das produções textuais da Psicologia Social Comunitária no Brasil entre os anos de 1990 e 2010 (Dissertação de mestrado). Universidade Federal do Rio de Janeiro, Rio de Janeiro, RJ, Brasil. Recuperado de http://objdig.ufrj.br/30/teses/824867.pdf

Gonçalves, M. A. (2019). Psicologia favelada: Ensaios sobre a construção de uma perspectiva popular em psicologia. Rio de Janeiro: Mórula.

Gonçalves, M. A., \& Portugal, F. (2016). Análise histórica da psicologia social comunitária no Brasil. Psicologia \& Sociedade, 28(3), 562-571. doi:10.1590/180703102016v28n3p562

Lacerda Jr., F. (Org.). (2017). Crítica e libertação na psicologia: Estudos psicossociais. Petrópolis, RJ: Vozes.

Lacerda Jr., F., \& Guzzo, R. (2009). Sobre o Sentido e a Necessidade: O resgate crítico da obra de Martín-Baró. In R. Guzzo \& F. Lacerda Jr. (Orgs), Psicologia social para a América Latina: O resgate da Psicologia da Libertação (pp. 15-37). Campinas, SP: Alínea.

Martín-Baró, I. (1996). O papel do Psicólogo. Estudos de psicologia, 2(1), 7-27. doi:10.1590/S1413-294X1997000100002. (Obra original publicada em 1985)

Martín-Baró, I. (2009). Para uma psicologia da libertação. In R. S. L. Guzzo, \& F. Lacerda Jr. (Orgs), (2009) Psicologia social para a América Latina: O resgate da Psicologia da libertação (pp. 101-120). Campinas, SP: Alínea. (Obra original publicada em 1986)

Martín-Baró, I. (2009). Desafios e perspectivas da psicologia latino-americana. In R. Guzzo \& F. Lacerda Jr. (Orgs), Psicologia social para a América Latina: O resgate da Psicologia da Libertação (pp. 199-219). Campinas, SP: Alínea. (Obra original publicada em 1989)

Martín-Baró, I. (2017). O psicólogo no processo revolucionário. In F. Lacerda Jr. (Org.), Crítica e libertação na psicologia: Estudos psicossociais (pp.25-29). Petrópolis, RJ: Vozes. (Obra original publicada em 1980)

Martín-Baró, I. (2017). A desideologização como contribuição da psicologia social para o desenvolvimento da democracia na América Latina. In F. Lacerda Jr. (Org.), Crítica e 
libertação na psicologia: estudos psicossociais (pp. 81-84). Petrópolis, RJ: Vozes. (Obra original publicada em 1985)

Martín-Baró, I. (2017). O desafio popular à psicologia social na América Latina. In F. Lacerda Jr. (Org.), Crítica e libertação na psicologia: Estudos psicossociais (pp. 6688). Petrópolis, RJ: Vozes. (Obra original publicada em 1987)

Ribeiro, D. (2016). Prefácio. In A. Davis, Mulheres, raça e classe (pp. 12-14). São Paulo: Boitempo.

\section{Endereço para correspondência}

\section{Mariana Alves Gonçalves}

Rua Engenheiro Ernani Cotrim, 85, 104, Tijuca, Rio de Janeiro - RJ, Brasil. CEP 20510-260

Endereço eletrônico: mariana.alvespsi@gmail.com

Recebido em: 12/09/2019

Reformulado em: 10/01/2020

Aceito em: 16/02/2020

\section{Notas}

* Doutora e mestre em Psicologia pela Universidade Federal do Rio de Janeiro (UFRJ). É professora universitária e pesquisadora, com experiência em Psicologia Social.

Financiamento: $\mathrm{O}$ artigo foi resultado do processo de pesquisa de doutorado, que recebeu financiamento da CAPES.

Este artigo de revista Estudos e Pesquisas em Psicologia é licenciado sob uma Licença Creative Commons Atribuição-Não Comercial 3.0 Não Adaptada. 